\title{
Ozone Decomposition in Four Types of Spouted Beds, With or Without a Draft-Tube
}

\author{
Hirotsugu HATTORI ${ }^{\dagger}{ }^{\dagger}$, Eiki HATA and Tsukasa UCHINO \\ Department of Fine Materials Engineering, \\ Faculty of Textile Science and Technology, \\ Shinshu University, 3-15-1, Tokida, Ueda-shi, Nagano 386-8567, Japan
}

E-mail: hhatori@shinshu-u.ac.jp

Phone: +81-268-21-5460

Fax: +81-268-21-5321

Partly presented at the 70th Annual Meeting of the Society of Chemical Engineers, Japan at Nagoya, March, 2005

Keywords: Spouted Bed, Top-Sealed Spouted Bed, Screen-Bottomed Spouted Bed, Ozone Decomposition, Gas Conversion

Ozone decomposition on the iron oxide catalyst was carried out in four types of spouted beds and the gas conversions were compared, for the purpose of comparing the gas-solid contacting efficiency of these spouted beds. These four types include a top-sealed spouted bed, a screen-bottomed spouted bed, and top-outlet spouted bed with or without a draft-tube. The top-sealed spouted bed and the screen-bottomed spouted bed provided higher gas conversion compared with the other two types of spouted beds. The gas-solid contacting efficiency of these spouted beds was compared with that of a hypothetically isothermal fixed bed. The top-outlet spouted bed with a draft-tube provided poorer contacting efficiency than the other types of spouted beds.

\section{Introduction}

In a commonly used top-outlet spouted bed, a large amount of gas passes through the spout without percolating through the annulus. This is not desirable for the spouted bed to be used as a gas-solid contact system, because the gas-solid contact mainly takes place in the annulus. Mathur and Lim (1974) predicted the chemical conversion for a spouted bed reactor. They described that the spouted bed, in common with a fluidized bed, is always a less efficient system for gas conversion than a hypothetically isothermal fixed bed.

To improve the efficiency of the spouted bed as a gas-solid contact system, we modified the structure of the spouted bed, and proposed this modification in the previous paper. The upper part of the vessel was closed and the gas flow pattern was changed in such a way that all the gas necessarily percolates through the annulus, as shown in Figure 1 (a) (Hattori et al., 1984). This spouted bed was called a "top-sealed spouted bed" (Hattori et al., 2001). In Figure 1, the gas flow pattern was illustrated by arrows.

In addition, another modified spouted bed, as shown in Figure 1 (b), was proposed in the previous paper (Hattori and Nagai, 1996; Hattori et al., 1998). It was called the "screen-bottomed spouted bed". The screen-bottomed spouted bed had no gas inlet nozzle or orifice and the gas was fed uniformly over the cross section of the vessel. The screen-bottomed spouted bed had a higher flow ratio of the gas percolating through the annulus than the ordinary spouted bed with a gas inlet nozzle or orifice.

These characteristics of the top-sealed spouted bed and the screen-bottomed spouted bed would provide high efficiency when these spouted beds are used as a chemical reactor.

In this study, ozone decomposition on an iron oxide catalyst was carried out in the above-mentioned spouted beds, and their conversion was compared among them to discuss the gas-solid contacting efficiency of these spouted beds. As suggested by Mathur and $\operatorname{Lim}(1974)$ and by Piccinini et al., (1979) the ozone decomposition on the iron oxide catalyst is a simple first-order reaction, and has a moderately fast reaction rate at room temperature.

\section{Experimental Apparatus and Procedure}

Three kinds of spouted bed with a draft-tube and one kind without a draft-tube were used, as shown in Figure 1. These were (a) top-sealed spouted bed, (b) screen-bottomed spouted bed, (c) top-outlet spouted bed with a draft-tube and (d) top-outlet spouted bed without a draft-tube, 
respectively. These were not half-sectional columns, but cylindrical columns. The column wall was made of acrylic resin and the draft-tube was made of thin steel plate of 0.3 $\mathrm{mm}$ in thickness. A 40-mesh screen was attached at the gas inlet of each spouted bed.

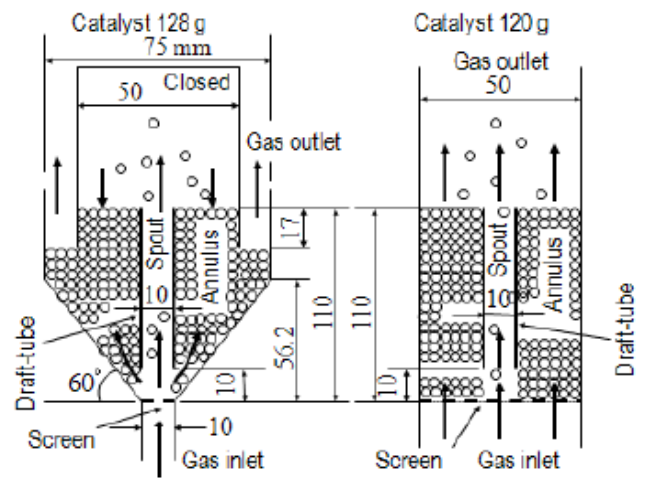

(a) Top-sealed spouted bed

(b) Screen-bottomed spouted bed
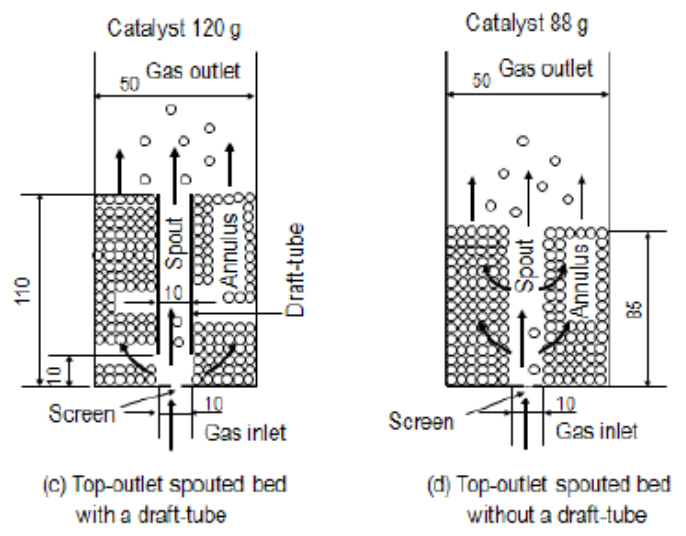

Fig.1 Four types of spouted beds

A flow sheet of the experimental setup is shown in Figure 2. Dry air at room temperature and of a constant dew point of $-40^{\circ} \mathrm{C}$ was mixed with a stream of ozone gas generated from pure oxygen using an ultra-violet ozone generator. The ozone concentration in the gas after mixing was about $2-10 \times 10^{-2} \mathrm{~mol} / \mathrm{m}^{3}$.

Iron oxide catalyst was made as follows: Spherical porous particles of activated alumina were outgassed in a vacuum desiccator and were immersed in an aqueous solution of iron( III ) nitrate. The wet particles were dried at room temperature for a few days and heated first in an electric oven at $100^{\circ} \mathrm{C}$ and then in an air-fluidized bed set in a electric furnace at $450^{\circ} \mathrm{C}$ for about $2 \mathrm{~h}$ each. The average diameter of the catalyst particles was $1.8 \mathrm{~mm}$ and particle density was $1.02 \times 10^{3} \mathrm{~kg} / \mathrm{m}^{3}$.

Gas samples were collected at the bed inlet and at the bed outlet. For the spouted beds excluding the top-sealed spouted bed, the outlet gas was sampled at a position sufficiently above the bed surface ( $340 \mathrm{~mm}$ above the bed surface), so that the gases from the spout and from the annulus were well mixed. For the top-sealed spouted bed, the gas was also sampled from the sealed top space as well as from the gas outlet. The gas samples were led to an ultra-violet spectrophotometer equipped with a flow cell. Absorbance at $254 \mathrm{~nm}$ wavelength was measured to determine ozone gas concentration. Sampling lines consisted of glass or Teflon tubes and cocks. No reaction occurred in the blank test using the alumina particles in which the iron oxide catalyst was not included.

Since the catalyst activity depends on the moisture contained in the particles, the experiments were carried out after dry air passed through the spouted beds for several hours. The spouted beds were operated at ambient temperature. The temperature in the gas inlet of each spouted bed was kept at $27^{\circ} \mathrm{C}$ by controlling the ambient temperature.

The catalyst activity was measured using a small-sized fixed bed immersed in a thermostat at the same temperature. A glass column of $15 \mathrm{~mm}$ in diameter was used for the fixed bed. In the fixed bed, the catalyst particles were packed as high as several times the column diameter. The activity, the rate constant of the first order reaction based on the volume of catalyst $k$, was calculated assuming that the flow in the fixed bed was a plug flow by Eq.(1).

$$
k=(v / M) \ln \left(C_{\text {in }} / C_{\text {out }}\right) \rho_{\text {s }}
$$

The apparent reaction rate constant was $20 \mathrm{~m}^{3}$ gas $/\left(\mathrm{m}^{3}\right.$ cat $\left.\cdot \mathrm{s}\right)$.

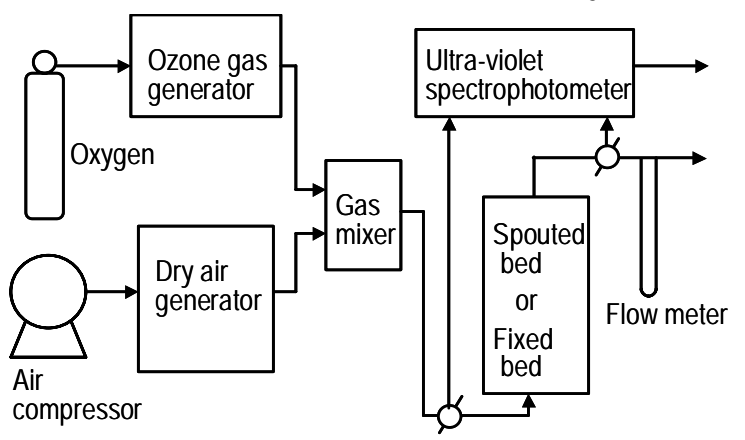

Fig.2 Flow sheet of experimental apparatus

When a first-order reaction is carried out in a flow reactor, the gas conversion depends on the product of the reaction rate constant and the gas-solid contact time within the reactor, as suggested in our previous paper (Takeda and Hattori, 1976). There exist moderate reaction rate and moderate gas-solid contact time that provide the difference in gas conversion to the reactor of different gas-solid contacting efficiency. In the present study, the catalyst activity and the sizes of the spouted beds were chosen in such a way that the difference in gas conversion appeared clearly among the various types of the spouted beds.

\section{Results and Discussion}

Figure 3 shows the gas conversion for the four types of spouted beds. The abscissa shows the volumetric gas flow rate and the ordinate the gas conversion. Both the top-sealed spouted bed and the screen-bottomed spouted bed provided higher gas conversion than the top-outlet spouted beds with and without a draft-tube.

The gas conversion can easily be compared if these 
spouted beds have the same amount of catalyst particles and are operated at the same gas flow rate. In this study, the amounts of solid catalyst or holdup of the catalyst particles were maintained at about the same level of $120 \mathrm{~g}$, as shown in Figure 3, excluding the top-outlet spouted bed without a

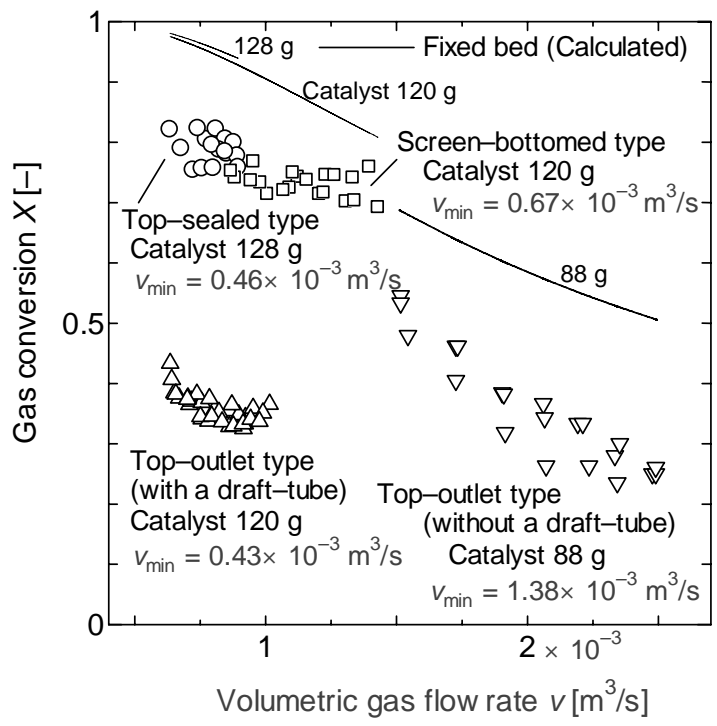

Fig.3 Gas conversion for four types of spouted beds

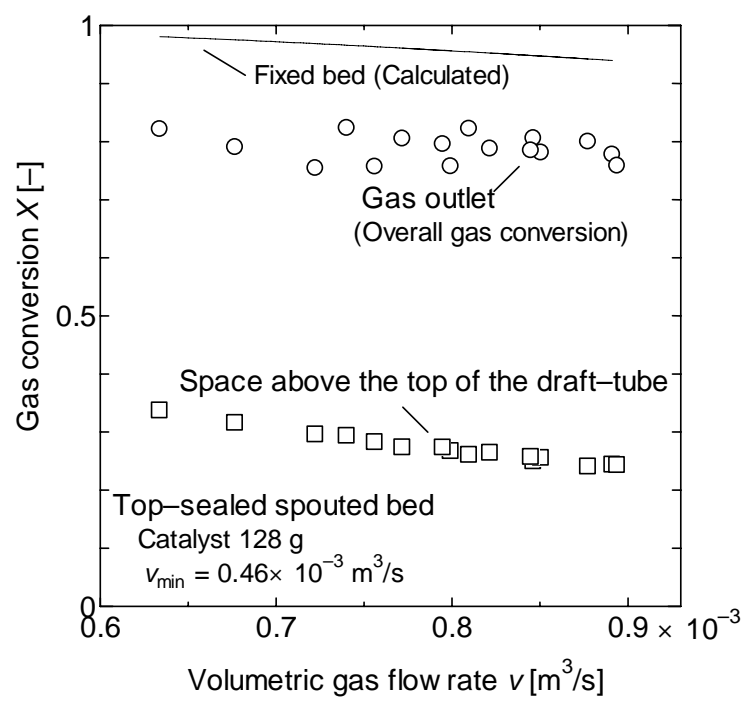

Fig.4 Gas conversion for the top-sealed spouted bed

draft-tube. In the case of the top-outlet spouted bed without a draft-tube, the holdup of the catalyst particles was $88 \mathrm{~g}$. More particles could not be spouted in this type of spouted bed because the bed height exceeded the maximum spoutable height.

The four spouted beds were operated at different gas flow rates. So, the gas conversions were also calculated for the fixed beds operated at the same gas flow rate and have the same catalyst holdup as each of the spouted beds. The calculated conversions were illustrated by solid lines in Figure 3. By comparing the gas conversion of each spouted bed with that of the corresponding fixed bed, it can be seen whether the spouted bed provides gas conversion close to that of the fixed bed or not. In the cases of the screen-bottomed spouted bed and the top-outlet spouted bed with a draft-tube, the gas conversion of the corresponding fixed bed was shown by the same solid line, because both spouted beds have the same amount of solid catalyst. In Figure 3, both the top-sealed spouted bed and the screen-bottomed spouted bed provided gas conversion close to that of the corresponding fixed bed. The top-outlet spouted bed without a draft-tube showed poor gas conversion in Figure 3. However, the corresponding fixed bed also showed poor gas conversion because of the smaller catalyst holdup and higher operating gas flow rate. While in the case of the top-outlet spouted bed with a draft-tube, the gas conversion was significantly lower compared with the corresponding fixed bed.

For the top-sealed spouted bed, the conversion was also measured for the gas that had reached upper space above the top of the draft-tube, in addition to the overall gas conversion. These were shown in Figure 4. It was found that the conversion of the gas at the space was as poor as about 0.3 , although the overall gas conversion was as high as about 0.8. Advantageous characteristics of the top-sealed spouted bed were made clear from these results. In the top-sealed spouted bed, the gas that has passed through the draft-tube then changes direction and travels downward again through the annular solid bed before it reaches the gas outlet. The poor conversion of the gas in the top space is improved while the gas again passes through the annulus.

To compare the gas-solid contacting efficiency of each type of spouted bed, the relation between $-\ln (1-X)$ and $k M /\left(\rho_{\mathrm{s}} v\right)$ was plotted in Figure 5, after Kunii and Levenspiel (1991). In Figure 5, the relation for a fixed bed is shown in a straight line with slope equal to 1 . Excluding the top-outlet spouted bed with a draft-tube, the relations for three other spouted beds were roughly approximated by

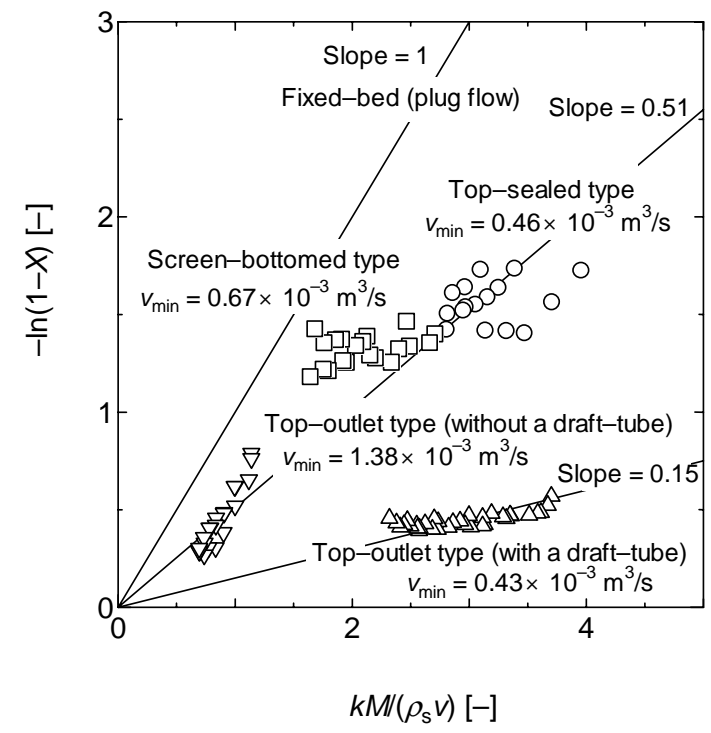

Fig.5 Comparison of the gas-solid contacting efficiency with the fixed-bed 
a straight line with a slope of 0.51, as shown in Figure 5. Also as seen from the Figure, these three spouted beds provide nearly the same gas-solid contacting efficiency.

However, for the top-outlet spouted bed without a draft-tube, it is difficult to achieve high gas conversion when the reaction rate is low. In this spouted bed, the amount of solid particles in the vessel is restricted because of the maximum spoutable bed height, which is inherent to this type of spouted bed. In addition, the gas flow rate must increase to maintain stable spouting, otherwise the annular solid bed collapses. On the other hand, the top-sealed spouted bed and the screen-bottomed spouted bed can be operated at lower gas flow rates, because the draft-tube prevents the annular solid bed from collapsing. These spouted beds are useful to achieve high gas conversion when the reaction rate is low.

In the case of the top-outlet spouted bed with a draft-tube, the relation between $-\ln (1-X)$ and $k M /\left(\rho_{\mathrm{s}} v\right)$ deviated far from that for the fixed bed, as shown in Figure 5. This type of spouted bed provides poor gas-solid contacting efficiency, because the draft-tube prevents the gas from flowing out of the spout to the annulus, and then a large amount of gas passes only through the spout without percolating through the annulus.

\section{Conclusions}

Ozone decomposition on the iron oxide catalyst was carried out in four types of spouted beds with or without a draft-tube and their conversion was compared. The two modified spouted beds, a top-sealed spouted bed and a screen-bottomed spouted bed, provided higher gas conversion compared with the other types of spouted beds. To compare the gas-solid contacting efficiency of each type of spouted bed, the relation between $-\ln (1-X)$ and $k M /\left(\rho_{\mathrm{s}} v\right)$ was plotted. The relations for three types of spouted beds, excluding the top-outlet spouted bed with a draft-tube, were roughly approximated by the same straight line. These three spouted beds provided nearly the same gas-solid contacting efficiency. The top-outlet spouted bed with a draft-tube provided the poorest efficiency of all four types of spouted beds.

\section{Acknowledgments}

We would like to express our thanks to Dr. Masaaki Nakamura of Nagoya University for his helpful discussions.

\section{Nomenclature}

$$
\begin{aligned}
& C_{\text {in }}=\text { ozone concentration at the bed inlet } \quad\left[\mathrm{mol} / \mathrm{m}^{3}\right] \\
& C_{\text {out }}=\text { ozone concentration at the bed outlet } \quad\left[\mathrm{mol} / \mathrm{m}^{3}\right] \\
& k=\text { rate constant of the first order reaction based on the } \\
& \text { catalyst volume } \quad\left[\mathrm{m}^{3} \text { gas } /\left(\mathrm{m}^{3} \text { cat } \cdot \mathrm{s}\right)\right] \\
& M=\text { amount of solid catalyst in the vessel } \quad[\mathrm{kg}] \\
& v=\text { volumetric flow rate of gas }\left[\mathrm{m}^{3} / \mathrm{s}\right] \\
& v_{\min }=\text { minimum of the volumetric flow rate of gas }\left[\mathrm{m}^{3} / \mathrm{s}\right] \\
& X=\text { gas conversion } \\
& \text { [-] }
\end{aligned}
$$

$\rho_{\mathrm{S}}=$ density of catalyst particles

$\left[\mathrm{kg} / \mathrm{m}^{3}\right]$

\section{Literature Cited}

Hattori, H. and T. Nagai; "Spouted Bed with a Draft-Tube without Gas Inlet Nozzle or Orifice, ”J. Chem. Eng. Japan, 29, 484-487 (1996)

Hattori, H., A. Kobayashi, I. Aiba and T. Koda; "Modification of the Gas Outlet Structure on the Spouted Bed with Inner Draft-Tube, ”J. Chem. Eng. Japan, 17, 102-103 (1984)

Hattori, H., T. Nagai, Y. Ohshima, M. Yoshida and A. Nagata; "Solids Circulation Rate in Screen-bottomed Spouted Bed with Draft-Tube, ”J. Chem. Eng. Japan, 31, 633-635 (1998)

Hattori, H., T. Morimoto, M. Yamaguchi, T. Onezawa and C. Arai; "Drying of Porous Solid Particles in Various-Shaped Spouted Bed with a Draft-Tube, ”J. Chem. Eng. Japan, 34, 1549-1552 (2001)

Kunii, D. and O. Levenspiel; Fluidization Engineering, 2nd ed., pp. 277-282, John Wiley \& Sons, New York, U.S.A. (1991)

Mathur, K. B. and C. J. Lim; "Vapour Phase Chemical Reaction in Spouted Beds: A Theoretical Model, ”Chem. Eng. Sci., 29, 789-797 (1974)

Piccinini, N., J. R. Grace and K. B. Mathur; "Vapour Phase Chemical Reaction in Spouted Beds: Verification of Theory, ”Chem. Eng. Sci., 34, 1257-1263 (1979)

Takeda, K. and H. Hattori; "Calculation of Gas Conversion for Top-Outlet Type and Side-Outlet Type Spouted Beds - First Order Solid-Catalyzed Reaction - , "Kagaku Kogaku Ronbunshu, 2, 507-511 (1976) 